\title{
Conectados pela ficção: circulação e leitura de romances entre a Europa e o Brasil
}

Márcia Abreu

UNICAMP

Resumo: Este artigo tem por propósito apresentar e analisar as conexões culturais estabelecidas entre a Europa e o Brasil por meio da leitura de romances em circulação na primeira metade do século XIX e discutir o impacto que a consideração do gosto dos leitores pode ter para a historiografia literária. Para tanto, o texto se divide em três partes. $\mathrm{Na}$ primeira, apresentam-se dados sobre o comércio e leitura de livros no Rio de Janeiro e em Paris, a fim de dar a conhecer os romances que despertaram maior interesse nesses lugares. Na segunda, tecem-se consideraçôes sobre a maneira pela qual os letrados receberam os romances na Europa e no Brasil na primeira metade do século XIX. Na terceira e última parte discutem-se as consequências que o conhecimento das preferências dos leitores e dos modos de avaliação da crítica podem ter para a história da literatura. Palavras-chave: Romance, Globalização, História da literatura.

1. Este trabalho vem sendo desenvolvido com auxílio da FAPESP, como parte do Projeto Temático Circulação Transatlântica dos Impressos, e com apoio de uma bolsa de produtividade em pesquisa do CNPq. Versões preliminares das ideias desenvolvidas neste artigo foram debatidas no "IV Seminário de Pesquisas em Literatura Brasileira: Leituras do romance brasileiro" (UFMG, 2011); Colóquio "A Circulação Transatlântica dos Impressos - conexões" (USP, 2012), "Escola São Paulo de Estudos Avançados sobre a Globalização da Cultura no Século XIX”... 


\section{As preferências dos leitores}

No século XIX, não havia ainda as famosas listas de livros mais vendidos publicadas em periódicos do nosso tempo, mas é possível reconstituir a preferência dos leitores consultando fontes diversas, como pedidos de licença para circulação de livros submetidos à censura, anúncios publicados por livreiros em jornais de grande circulação, dados sobre tiragens e registros de consultas de obras em bibliotecas.

É possível ter uma ideia bastante clara sobre os livros em circulação no Rio de Janeiro nas primeiras décadas do século XIX consultando os registros de censura relativos à entrada e saída de livros nos portos. Uma primeira informação interessante é a grande procura por obras de ficção em prosa: entre 1795 e 1822, em torno de $50 \%$ das obras de Belas Letras mais enviadas de Lisboa para o Rio de Janeiro são narrativas ficcionais. ${ }^{2}$ Esse interesse pela ficção concentrava-se em algumas obras, sistematicamente enviadas da Europa para o Rio de Janeiro, como se vê nas listas abaixo, que apresentam os romances preferidos entre 1795 e 1807 (submetidos à censura lusitana), entre 1808 e 1822 (que se subdividem entre os submetidos à censura em Lisboa e os apresentados no Rio de Janeiro):

\begin{tabular}{|c|c|c|}
\hline $\begin{array}{l}\text { Romances preferidos entre } \\
1795 \text { e } 1807 \text { (censura Lisboa) }\end{array}$ & $\begin{array}{l}\text { Romances preferidos entre } \\
1808 \text { e } 1822 \text { (censura Lisboa) }\end{array}$ & $\begin{array}{c}\text { Romances preferidos entre } \\
1808 \text { e } 1822 \text { (censura Rio de Janeiro) }\end{array}$ \\
\hline $\begin{array}{l}\text { Aventuras de Telêmaco, Fénelon } \\
\text { História de Gil Blas, Lesage } \\
\text { Carolina de Litchfield, Montolieu } \\
\text { Dom Quixote, Cervantes } \\
\text { História do Imperador Carlos } \\
\text { Magno, anônimo } \\
\text { Lances da Ventura, Monroy y Ros } \\
\text { Viagens de Altina, Campos } \\
\text { Viagens de Henrique Wanton, } \\
\text { Seriman } \\
\text { O Feliz independente, Almeida } \\
\text { Aventuras de Diófanes, Orta }\end{array}$ & $\begin{array}{l}\text { Aventuras de Telêmaco, Fénelon } \\
\text { Mil e uma noites, Galland } \\
\text { História de Gil Blas, Lesage } \\
\text { Tesouro de meninas, Beaumont } \\
\text { História do Imperador Carlos } \\
\text { Magno, anônimo } \\
\text { O Feliz independente, Almeida } \\
\text { Lances da Ventura, Monroy y Ros } \\
\text { Tesouro de Meninos, Blanchard } \\
\text { O Piolho Viajante, Silva } \\
\text { Dom Quixote, Cervantes }\end{array}$ & $\begin{array}{l}\text { Aventuras de Telêmaco, Fénelon } \\
\text { História de Gil Blas, Lesage } \\
\text { Voyage du Jeune Anacharsis en } \\
\text { Grèce, Barthélemy } \\
\text { Dom Quixote, Cervantes } \\
\text { Robinson Crusoe, Defoe } \\
\text { Oeuvres, Lesage } \\
\text { Paulo e Virginia, B. Saint-Pierre } \\
\text { Oeuvres, Prevost } \\
\text { Scènes de la vie du grand monde, } \\
\text { Edgeworth }\end{array}$ \\
\hline
\end{tabular}

Tabela 1: Romances de maior frequência em pedidos de licença submetidos à censura em Lisboa e no Rio de Janeiro ${ }^{3}$

1. ... (UNICAMP e USP, 2012). Graças às instigantes críticas e sugestões recebidas, algumas interpretações foram alteradas, outras, reforçadas. Uma versão anterior da parte inicial deste texto foi publicada na revista argentina Orbis Tertius, ano XVII, número 18, 2012.

2. Cf. ABREU. Os caminhos dos livros.

3. Para o estabelecimento destas listas, foi computado o número de pedidos de autorização para remessa de livros de Lisboa para o Rio de Janeiro e selecionados os 10 títulos ficcionais mais requeridos. Fonte: Arquivo Nacional da Torre do Tombo (Fundo Real Mesa Censória) e Arquivo Nacional do Rio de Janeiro (Fundo Mesa do Desembargo do Paço). 
Essas listagens podem causar algum espanto, já que poucos terão ouvido falar de grande parte dessas obras. Pode ser surpreendente também o fato de não haver produções recentes nessas listas. Com exceção de $O$ piolho viajante e Tales of fashionable life ${ }^{4}$, publicados no início do XIX, todos os demais tiveram sua primeira edição no século XVIII. ${ }^{5}$ A estabilidade na predileção dos leitores se percebe não apenas no fato de os livros mais importados terem sido compostos em séculos anteriores, mas também pela permanência no interesse com o passar dos anos. Muitos dos títulos apreciados até 1807 permanecem em destaque até 1821, quando foi abolida a censura preventiva e suspenso o controle de livros nas alfândegas, revelando que as mudanças sócio-político-econômicas de grande monta ocorridas no Brasil no início do XIX não afetaram de maneira significativa o gosto dos leitores. Os acontecimentos das primeiras décadas de vida independente também não parecem ter abalado as preferências de leitura, uma vez que os livreiros mantiveram as obras mais importadas no período colonial em destaque nos anúncios que publicavam nos principais jornais da corte. Pesquisa de Mestrado realizada por Regiane Mançano levantou os seguintes dados sobre os anúncios de romances publicados no Jornal do Commercio:

4. O livro de Maria Edgeworth, Tales of fashionable life, é referido em todos os pedidos de licença na versão em francês, Scènes de la vie du grand monde, razão pela qual seu título está em francês na tabela. Os demais livros são pedidos em diversas línguas, por isso foram indicados em português.

5. As primeiras edições em língua original ocorreram nas seguintes datas: Aventuras de Telêmaco, Fénelon (1699); Carolina de Litchfield, Montolieu (1786); Dom Quixote, Cervantes (1605-1615); História de Gil Blas, Lesage (1715); História do Imperador Carlos Magno, anônimo (1490); Lances da ventura, Monroy y Ros (1793-97); Mil e uma noites, Galland (1704-1717); O Feliz independente, Almeida (1779); O piolho viajante, Silva (1802); Oeuvres, Lesage; Oeuvres, Prevost; Paulo e Virginia, B. Saint-Pierre (1788); Robinson Crusoe, Defoe (1719); Tales of fashionable life, Edgeworth (1809-1812); Tesouro de meninas, Beaumont (1757); Tesouro de meninos, Blanchard (1802); Viagens de Altina, Campos (1790-93); Viagens de Henrique Wanton, Seriman (1749); Voyage du Jeune Anacharsis en Grèce, Barthélemy (1788). Não foi possível localizar a data da primeira edição de Le Buffon de La Jeunesse (Tesouro de meninos). A segunda edição saiu em 1802 e a terceira em 1804, de modo que, provavelmente, a primeira deve ter saído no final do século XVIII. 


$\begin{array}{ll}\text { Aventuras de Telêmaco, Fénelon (1699) } & 1810-1843 \\ \text { História de Gil Blas, Lesage (1715) } & 1810-1843 \\ \text { Choupana índia, B. Saint-Pierre (1790) } & 1811-1843 \\ \text { Diabo Coxo, Lesage (1707) } & 1811-1843 \\ \text { Paulo e Virginia, B. Saint-Pierre (1788) } & 1811-1843 \\ \text { Cartas de uma peruviana, Mme Graffigny (1747/52) } & 1811-1843 \\ \text { Filósofa por amor, Rétif de La Bretonne (1766) } & 1811-1843 \\ \text { Ilha incógnita, Guillaume Grivel (1784) } & 1811-1843 \\ \text { Lances da Ventura, Monroy y Ros (1793) } & 1811-1843 \\ \text { Thesouro de meninas, Beaumont (1757) } & 1811-1843\end{array}$

Tabela 2: Romances mais longamente anunciados no Jornal do Commercio

Os títulos anunciados por mais tempo são muito semelhantes aos mais remetidos da Europa para o Rio de Janeiro no período colonial. Reitera-se o interesse por Aventuras de Telêmaco, Gil Blas, Paulo e Virgínia, Lances da ventura e Tesouro de meninos. Até mesmo as "novidades" não são assim tão recentes, tendo em vista que todos os títulos anunciados tiveram sua primeira edição no século XVIII, permanecendo em destaque por cem ou mais anos.

Grande parte destas obras também faz parte das listas de títulos mais procurados por leitores na Biblioteca Nacional e Pública do Rio de Janeiro. Embora a instituição não tivesse um acervo predominantemente voltado para a literatura - e muito menos para os romances - pessoas a frequentavam em busca de obras ficcionais, segundo revelou a Dissertação de Mestrado de Débora Bondance Rocha, que consultou os livros de registro mantidos pela biblioteca entre 1833 e 1856 . $^{7}$

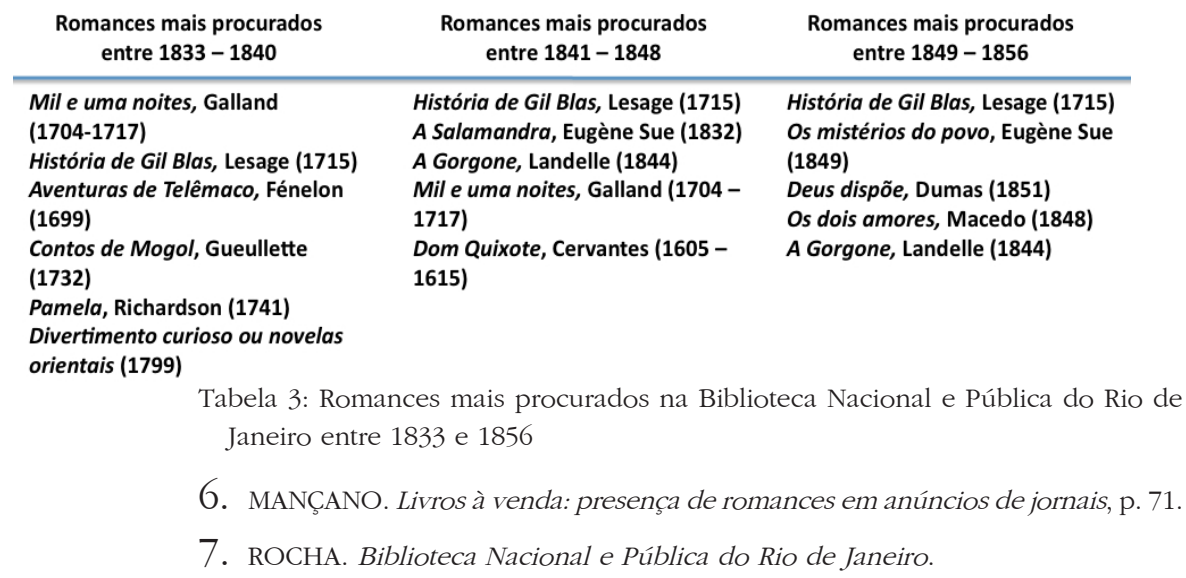


Num primeiro momento, compreendido entre o início da atividade de registro das consultas até o princípio da publicação de folhetins no Brasil (que se deu em 1839), o livro mais procurado pelos leitores é Mil e uma noites, obra já bem conhecida no Rio de Janeiro, tendo em vista ter sido importada com frequência e também propagandeada com constância nos jornais cariocas, nos quais há 41 anúncios deste título entre 1818 e $1843{ }^{8}$. Da mesma forma, tiveram destaque as leituras de narrativas há muito presentes na cidade, como Gil Blas e Telêmaco, que também tinham forte presença na publicidade do Jornal do Commercio, onde Telêmaco foi anunciado 134 vezes no período (1827-1844) e Gil Blas 89 vezes.

No segundo momento, marcado pelo início da publicação sistemática de romances-folhetins, o gosto dos leitores manteve-se bastante estável, persistindo a preferência por Gil Blas, Mil e uma noites e Dom Quixote. Entretanto, surgiram duas novidades: as obras A Salamandra e A Gorgone, compostas por folhetinistas de destaque no momento, Eugène Sue e Gabriel de La Landelle.

Em 1841, o Diário do Rio de Janeiro publicou o primeiro folhetim de Sue em terras brasileiras: Uma revolta no tempo do Império. A partir daí seu nome permaneceu nas páginas dos jornais, com destaque para a publicação de Os mistérios de Paris e O Judeu Errante, ambos publicados entre 1844-1845. ${ }^{9}$ O interesse provocado por essas narrativas pode ter levado leitores à biblioteca em busca de seus livros, o que talvez explique a grande procura por A Salamandra, romance publicado na França em 1832 e traduzido para o português em 1845. As consultas à obra de Gabriel de la Landelle parecem ainda mais fortemente ligadas aos folhetins, uma vez que todos os pedidos registrados pela biblioteca para A Gorgone, novela marítima, ocorreram no ano de $1848,{ }^{10}$ momento em que a obra estava sendo publicada em folhetim pelo Jornal do Commercio. ${ }^{11}$

As novidades acentuam-se no último período para o qual se conservam registros de consulta na Biblioteca Nacional. Excetuando-se a História de Gil Blas, no topo da lista, os demais romances tinham sido publicados,

8. Cálculo realizado por Débora Cristina Bondance Rocha a partir dos dados recolhidos por Regiane Mançano (nas obras citadas das respectivas autoras).

9. HEINEBERG. La suite au prochain numéro.

10. RocHA. Biblioteca Nacional e Pública do Rio de Janeiro, p. 89.

11.HEINEBERG. La suite au prochain numéro. 
em seus países de origem, há mais ou menos 5 anos, quando se tornaram os preferidos dos leitores da Biblioteca Nacional. Novamente, o folhetim pareceu agir como um fator de atração, pois, além de A Gorgone, há Os mistérios do povo (publicado no Correio Mercantil entre 1850 e 1852) e Deus dispõe (no Jornal do Commercio, entre 1851 e 1852). Maior novidade ainda é o aparecimento de um romance nacional na lista dos preferidos: Os dois amores, de Joaquim Manoel de Macedo. Também nesse caso, a publicação em folhetins parece ter contribuído para atrair o interesse dos leitores, pois a obra saiu nos rodapés do Correio Mercantil, em $1848 .^{12}$

Embora algumas obras compostas por autores brasileiros tenham sido procuradas na Biblioteca, ${ }^{13}$ os leitores não parecem muito sensíveis à questão da nacionalidade dos escritos, problema que tanto mobilizou os escritores naquele momento. Desde o início do século, seu interesse parece muito mais voltado para as obras de origem francesa. Dentre as solicitações de licença para obtenção de livros apresentadas à censura, 40\% dos romances mais referidos até 1807 foram originalmente escritos em francês, número que sobe para 65\% entre 1808 e 1822. A referência francesa é também expressiva dentre os romances longamente anunciados no Rio de Janeiro (dos quais 90\% foram originalmente escritos em francês) e dentre os mais consultados na Biblioteca Nacional (80\%).

A sintonia com a França é impressionante não apenas quando se considera a origem dos livros, mas também quando se observam os títulos pelos quais os leitores dos dois lados do Atlântico estavam interessados. ${ }^{14}$ Analisando as tiragens dos livros publicados na França entre 1813 e 1850, Martyn Lyons estabeleceu listas quinquenais de "best-sellers franceses", com o objetivo de conhecer "os sucessos de atualidade", "os sucessos de média duração" e "os sucessos de longa duração”. Interessa observar, sobretudo, os livros de longa presença nas preferências do público, pois, segundo o autor, "a análise dos

\section{HEINEBERG. La suite au prochain numéro.}

13. Os frequentadores da Biblioteca buscaram apenas seis romances brasileiros: Os dois amores, A Vicentina e A Moreninha, de Macedo; As tardes de um pintor, Gonzaga e A Providência, de Teixeira e Souza. A poesia nacional teve um desempenho bem melhor: Segundos cantos, de Gonçalves Dias teve destaque, ocupando o segundo lugar entre os livros de Belas Letras mais procurados entre 1849 e 1856, com 75 consultas, enquanto o terceiro lugar coube a Parnaso brasileiro, de João Manoel Pereira da Silva, com 63 consultas (ROCHA. Biblioteca Nacional e Pública do Rio de Janeiro, p. 95).

14. LYONS. Les best-sellers. In: CHARTIER \& MARTIN. Histoire de l'édition française. 
grandes sucessos duráveis deste último grupo coloca em evidência a continuidade fundamental do gosto popular francês, pois são eles que formam o fundo permanente da cultura literária francesa”.

\begin{tabular}{|c|c|c|c|c|c|c|c|c|c|}
\hline \multirow[t]{2}{*}{ Apreciados no Brasil } & \multicolumn{8}{|c|}{ Tiragem mínima produzida na França } & \multirow[t]{2}{*}{ Total } \\
\hline & $\begin{array}{l}1811- \\
1815\end{array}$ & $\begin{array}{l}1816- \\
1820\end{array}$ & $\begin{array}{l}1821- \\
1825\end{array}$ & $\begin{array}{l}1826- \\
1830\end{array}$ & $\begin{array}{l}1831- \\
1835\end{array}$ & $\begin{array}{l}1836- \\
1840\end{array}$ & $\begin{array}{l}1841- \\
1845\end{array}$ & $\begin{array}{l}1846- \\
1850\end{array}$ & \\
\hline Aventuras de Telêmaco, Fénelon & 15.500 & 11.000 & 42.800 & 58.500 & 33.700 & 29.500 & 62.200 & 5.500 & 258.700 \\
\hline Paulo e Virginia, B. Saint-Pierre & & 18.000 & & 18.000 & 16.000 & 13.000 & 15.500 & 23.000 & 103.500 \\
\hline História de Gil Blas, Lesage & 4.900 & 4.700 & 15.900 & 4.600 & 12.500 & 6.000 & 22.000 & & 70.600 \\
\hline Robinson Crusoe, Defoe & & & 4.000 & 23.000 & 14.000 & 4.500 & 13.500 & 2.000 & 61.000 \\
\hline Mil e uma noites, Galland & & & & & & 7.000 & 8.500 & 35.000 & 50.500 \\
\hline Dom Quixote, Cervantes & & & 17.300 & & & & 6.000 & & 23.300 \\
\hline Tesouro de Meninos, Blanchard & 3.500 & & 11.500 & 8.000 & & & & & 23.000 \\
\hline
\end{tabular}

Tabela 4: Romances apreciados no Brasil e na França - quadro comparativo

Se Martyn Lyons conhecesse as preferências dos leitores fluminenses, talvez modificasse um pouco seus comentários, observando que esses livros, na verdade, evidenciam a "continuidade fundamental do gosto popular" ocidental, formando "o fundo permanente da cultura literária" mundial, tendo em vista o simultâneo interesse por livros como Aventuras de Telêmaco, História de Gil Blas, Robinson Crusoé, Paulo e Virgínia, Dom Quixote, Tesouro de meninas e Mil e uma noites. As coincidências não se limitam aos chamados "sucessos de longa duração". Quando se consideram os "sucessos de média duração" também há semelhanças entre o que se verifica na França e o que ocorre no Rio de Janeiro, principalmente no meado do século, quando Eugène Sue e Alexandre Dumas obtêm destacadas tiragens na França - muito embora se mantenham atrás dos números referentes a Aventuras de Telêmaco (entre 1841-45) e As mil e uma noites (entre 1846-50). ${ }^{16}$ Observa-se, assim, uma impressionante sincronia nas leituras e uma forte conexão no mercado editorial, que colocava à venda as mesmas obras, em diferentes partes do mundo, no mesmo período. Fica evidente, também, a existência de um gosto literário globalizado, profundamente marcado pelas obras francesas do século XVII e XVIII e pelas referências clássicas. ${ }^{17}$

15. LYONS. Les best-sellers. In: CHARTIER \& MARTIN. Histoire de l'édition française, p. 421.

16. LYONS. Les best-sellers. In: CHARTIER \& MARTIN. Histoire de l'édition française, p. 425.

17. Para uma discussão sobre a globalização da cultura, ver GRUZINSKY. Les quatres parties du monde - histoire d'une mondialisation. Para uma reflexão sobre o conceito de globalização, ver COOPER. "What is the concept of globalization good for? An African historian's perspective". 
Entretanto, importa considerar também algumas discrepâncias no gosto francês e brasileiro. Chama atenção, por exemplo, a pequena relevância da obra de Rousseau, Julie ou la Nouvelle Heloïse (1761), no Rio de Janeiro na primeira metade do século XIX. Segundo Lyons este foi "o romance mais vendido no século XVIII ${ }^{18}$ - regularmente reeditado durante a primeira metade do século XIX", contando com 55 edições entre 1816 e 1850. A pequena quantidade de referências à obra na documentação submetida ao controle da censura instalada em Lisboa e no Rio de Janeiro é fácil de compreender quando se sabe que ela foi proibida de circular pelo Alvará de 24 de setembro de $1770{ }^{19}$ mantendo-se a proibição no século XIX. Se a interdição censória não impediu o acesso ao livro, como se percebe nos vários documentos de proibição exarados pelos organismos de censura, ${ }^{20}$ impossibilitou, como é evidente, a publicação de traduções, o que só ocorreu em 1837..$^{21}$ Assim, se seria incorreto dizer que a obra de Rousseau foi desconhecida em Portugal e no Brasil, é certo que a interdição censória e a consequente ausência de traduções impossibilitou a difusão da obra para grandes públicos.

A falta de tradução para o português parece estar na base de outro desajuste entre fluminenses e parisienses nos "sucessos de média duração": os casos de Walter Scott ${ }^{22}$ e Victor Hugo. ${ }^{23}$

18. LYONS. Les best-sellers. In: CHARTIER \& MARTIN. Histoire de l'édition française, p. 428.

19. VILlaLTA. Reformismo ilustrado, censura e práticas de leitura, p. 184.

20. Antes mesmo da inclusão de Julie ou la Nouvelle Heloïse no rol de livros proibidos, a obra já havia sido interditada em Portugal, em 18 de agosto de 1768, quando Frei Manuel do Cenáculo assim se pronunciou: "Lettres de deux Amants, por Joaõ Jacques Rousseau, conhecidas pelo nome de Julia, ou a Nova Heloisa, - saõ livros abominaveis, impurissimos, provocativos de corrupçaõ; e que devem ficar supprimidos." (Arquivo Nacional da Torre do Tombo - Real Mesa Censória - Censuras e Pareceres- Caixa 4, 1768, no 88, censura n. 20). O livro continuava proibido em 1807, quando foi indicada entre as "Obras licenciosas presentes na relação de livros de P. Gaubie” avaliadas pelo censor João Guilherme Christiano Müller (ANTT - Ministério do Reino - Consultas do Desembargo do Paço - 1807 - 1812 março 343, cxs 458-459).

21. OUTEIRINHO. As traduções da obra de Rousseau em Portugal: texto e paratexto. Revista da Faculdade de Letras Línguas e Literaturas, p. 398.

22. Walter Scott aparece nas listagens preparadas por Lyons no período 1826-1830, com Ivanhoé, L'Antiquaire, L'Abbé e Quentin Durward (que volta a aparecer em 1831-1835 e 1841-1845). Mas a partir de 1845 seu nome desaparece das listas. LYONS. Les best-sellers. In: CHARTIER \& MARTIN. Histoire de l'édition française, p. 424.

23. Segundo Lyons, "le successeur de Scott a été Victor Hugo, dont Notre Dame de Paris a été un des grands succès de cette période [1831-1835]. La plus grosse vague de réimpressions a suivi de peu la première publication". LYONS. Les best-sellers. In: CHARTIER \& MARTIN. Histoire de l'édition française, p. 425. 
Embora haja anúncios para romances de Walter Scott em jornais cariocas nas primeiras décadas do século XIX, todas as propagandas referem livros em inglês ou em francês, ${ }^{24}$ situação que se altera apenas depois de 1837 , quando surgem diversas traduções: Ivanhoé, Talisman e Os puritanos da Escócia em 1837; O misantropo e Quentino Durward, em 1838; A formosa donzella de Perth, em 1840; Guy Mannering, em 1842; A Prisão de Edimburgo, em 1844; Waverley, em 1844.

Só a partir deste momento seus livros ganharam algum destaque na propaganda dos jornais, sem empanar, entretanto, o brilho das velhas preferências. Enquanto as Aventuras de Telêmaco é anunciado 51 vezes entre 1838 e 1844, Talisman recebe 37 menções em propagandas, Os puritanos da Escócia, 19; Ivanhoé, 18, ficando atrás de Paulo e Virgínia e de História de Gil Blas, com 22 reclames. Ainda que se trate de um autor de língua inglesa e de uma tradução para o português, a relevância da França continua evidente, uma vez que a maioria dos livros anunciados foi publicada em Paris, pela Aillaud. ${ }^{25}$ Em datas muito próximas às francesas, há edições portuguesas de traduções de Scott, mas estas tiveram pouco ou nenhum destaque nos anúncios do Jornal do Commercio - das 10 obras traduzidas e publicadas em Portugal $^{26}$ apenas 2

24. VASCONCELOS. Cruzando o Atlântico: notas sobre a recepção de Walter Scott. In: ABREU. Trajetórias do romance, p. 362, 363.

25. O Talisman, ou Ricardo na Palestina. Paris: Livraria Portugueza de J. P. Aillaud, 1837. Tradutor: Caetano Lopes de Moura. Os puritanos da Escócia. Paris: J. P. Aillaud, 1837. Tradutor: Caetano Lopes de Moura. Ivanhoe, ou o regresso do cruzado. Paris: Livraria Portugueza de J. P. Aillaud, 1837. Tradutor: E. P. da Câmera. Quentino Durward, ou, O escossez na corte de Luiz XI. Paris: Livraria Portugueza de J. P. Aillaud, 1838. Tradutor: Caetano Lopes de Moura. A prisão de Edimburgo. Paris: J. P. Aillaud, 1844. Tradutor: Caetano Lopes de Moura. $O$ misantropo, ou o anão das pedras negras. Paris: Livraria Portugueza de J. P. Aillaud, 1838. Tradutor: Caetano Lopes de Moura. Waverley ou há sessenta annos. Paris: J. P. Aillaud, 1844. Tradutor: Caetano Lopes de Moura.

26. Kenilworth. Lisboa: Typ. Soc. Propagadora Conhecimentos Úteis, 1841. Tradutor: A. J. Ramalho e Sousa; O mosteiro. Lisboa: Typografia Rollandiana, 1842. Tradutor: Jose Maria de Sales Ribeiro; O abbade, seguimento do mosteiro. Lisboa: Typografia Rollandiana, 1844. Tradutor: Jose Maria De Sales Ribeiro; Os desposados. Lisboa: Impressão de Galhardo e Irmãos. 1837; Anna de Geierstein ou a donzella do nevoeiro. Lisboa: Typ. Soc. Propagadora Conhecimentos Úteis, 1843. Tradutor: A. J. Ramalho e Sousa; O official e fortuna. Lisboa: Imprensa Nacional, 1837. Tradutor: M. P. C. C. d'A. Kenilworth. Lisboa: Typ. Soc. Propagadora Conhecimentos Úteis, 1843. Tradutor: A. J. Ramalho e Sousa, 1841; Uma lenda de Montrose. Lisboa: Typ. de G. M. Martins, 1842. Trad. M. A. da Silva; Woodstock... 
(Guy Mannering, ou o astrologo e A formosa donzella de Perth, ou o dia de S. Valentim) receberam anúncios no periódico. Há, ainda, os casos de Ivanhoé e Waverley, cujas traduções foram publicadas tanto em Paris quanto em Lisboa, praticamente no mesmo ano.

A volumosa quantidade de títulos traduzidos indica a existência de um interesse por Scott no mundo de língua portuguesa, mas a inexistência de segundas edições das obras publicadas ${ }^{28}$ permite supor que a resposta do público não foi tão expressiva. No Brasil, não parece ter havido nada remotamente semelhante à febre de Scott que se alastrou pela Inglaterra no começo do século, uma vez que seus romances parecem ter atraído mais a atenção da crítica do que a dos leitores comuns. ${ }^{29}$

O pequeno interesse despertado por Scott entre os leitores do Rio de Janeiro parece se dever, em grande medida, ao momento em que surgem suas traduções, coincidindo com o início da publicação de folhetins, em 1839. Seu azar pode ter sido disputar a atenção dos leitores com escritores como Eugène Sue, que conquistou o público e mobilizou o mundo livreiro fluminense. Neste caso, volta a haver sincronia entre o público brasileiro e europeu, tendo

26. ... ou o cavaleiro. Lisboa: Typ. de G. M. Martins, 1843-44. Trad. M. A. da Silva; Guy Mannering, ou o astrólogo. Lisboa: Typographia de G. M. Martins, 1842. Tradutor: M. A. da Silva; A formosa donzella de Perth, ou o dia de S. Valentim. Lisboa: Typografia Rollandiana, 1840. Tradutor: Jose Maria de Sales Ribeiro.

27. Além das edições parisienses já mencionadas, há edições lisboetas de Ivanhoe (Ivanhoe, ou a cruzada britânica. Lisboa: Typ. J. B. Norando, 1838, Quintino Durward. Lisboa: Typ. Soc. Propagadora Conhecimentos Úteis, 1838-39. Tradutor: A. J. Ramalho E Sousa) e de Waverley, caso curioso, em que há 2 edições lisboetas, com intervalo de um ano: Waverley; ou, ha sessenta annos. Lisboa, Typ. Soc. Propagadora Conhecimentos Úteis, 1845. Waverley, ou ha sessenta annos. Lisboa: Typ. de G. M. Martins, 1844. Trad. M. A. da Silva.

28. A única obra para a qual se encontrou registro de uma segunda edição foi O misantropo, ou o anão das pedras negras, com uma primeira edição em 1838 e outra em 1858, ambas impressas em Paris.

29. Sandra Vasconcelos, em estudo da recepção de Scott no Brasil, identificou três textos críticos publicados no Rio de Janeiro: O Beija-Flor. Annaes Brasileiros de Sciencia, Política e Litteratura e etc (n. 1, 1830); PEREIRA DA SILVA, "Teatro da Praia de D. Maria - 1a representação da noiva de Lammermoot, drama em 5 actos, traduzido do francês, e tirado de um romance de Walter Scott". Jornal de Debates, (8 de junho de 1837); PEREIRA DA SILVA, "Literatura: os romances modernos e sua influência". Jornal de Debates, (23 de setembro de 1837). 
em vista não apenas o sucesso editorial mas também a proximidade nas datas de publicação no Rio de Janeiro e em Paris. Na França, Les Mystères de Paris começou a ser publicado em junho de 1842, saindo, no mesmo ano, a edição em livro. ${ }^{30}$ Enquanto isso, no Rio de Janeiro, o folhetim foi publicado entre setembro de 1844 e janeiro de 1845 , saindo o primeiro volume do livro um mês após o início da publicação do romance no rodapé do no Jornal do Commercio. ${ }^{31}$

O interesse restrito despertado pelas obras de Victor Hugo no Rio de Janeiro, na primeira metade do século XIX, parece ter explicação semelhante: a importância da tradução e do folhetim. Edições de seus livros em português começaram a ser feitas apenas na segunda metade do Oitocentos, com exceção de Nossa Senhora de Paris, publicada em Lisboa, em 1841, e é tardia a presença de Hugo nos rodapés dos jornais - Os miseráveis é publicado no Jornal do Commercio, em 1862; Os trabalhadores do mar, no Diário do Rio de Janeiro, em 1866 e O homem que ri, no Diário do Rio de Janeiro, entre 1869 e $1870 .^{33}$

Segundo Lyons, "Scott, Hugo, Sue e Dumas dominaram a edição durante duas ou três décadas e contribuíram largamente para o "triunfo do livro.", Entretanto, só tiveram importância numérica no Rio de Janeiro as obras dos autores traduzidos para o português - Sue e Dumas - o que mostra a relevância da edição em língua portuguesa para a difusão mundial dos romances.

30. A publicação dos Mystères de Paris teve início no dia 19 de junho de 1842 , mesmo ano em que saiu a edição em livro. SCHAPOCHNIK. Edição, recepção e mobilidade do romance Les Mystères de Paris no Brasil oitocentista. In: Varia história.

31. SCHAPOCHNIK. Edição, recepção e mobilidade do romance Les Mystères de Paris no Brasil oitocentista. In: Varia história.

32. Nossa Senhora de Paris, Lisboa: Typographia da Sociedade Propagadora dos Conhecimentos Úteis, 1841. Nos anos seguintes, foram publicados, no Brasil, Os miseráveis, Salvador: Livraria Progresso, 1864 e O homem que ri, Rio de Janeiro: Typ. do Diário do Rio de Janeiro, 1869.

33. Cf. "Index IV: Index général par auteur". HEINEBERG. La suite au prochain numéro.

34. LYONS. Les best-sellers. In: CHARTIER \& MARTIN. Histoire de l'édition française, p. 426. 


\section{A reação dos letrados aos romances}

O fato de haver semelhanças importantes entre os romances apreciados em Paris e no Rio de Janeiro desperta curiosidade em saber se a especificidade local estaria na forma pela qual os leitores se apropriaram dessas obras. Se as reações dos homens e mulheres que consultavam os jornais para saber onde comprar a História de Gil Blas ou que iam à biblioteca para ler As mil e uma noites estão perdidas para sempre, é possível recuperar as leituras feitas por um grupo específico de homens: os letrados que lidavam profissionalmente com os romances na Inglaterra, na França, em Portugal e no Brasil. Para observar suas reações, serão analisados dois tipos de escritos: textos de circulação ampla, publicados em periódicos ingleses, franceses, portugueses e brasileiros, e textos de circulação restrita a pequenos círculos letrados, produzidos por censores franceses, portugueses e luso-brasileiros a fim de autorizar a publicação ou a circulação de romances. ${ }^{35}$ A análise se concentrará nos anos compreendidos entre 1789 e 1839, ou seja, no período anterior à publicação de folhetins no Brasil (apenas três anos após seu surgimento na França), pois, como se viu, seu surgimento alterou de maneira importante o gosto do público, assim como provocou mudanças na maneira de produzir e avaliar as obras ficcionais.

Um primeiro elemento a destacar é o evidente desapreço em relação ao gênero romanesco, fator que irmana os letrados de diferentes partes da Europa e do Brasil, fazendo-os associá-lo à "mediocridade", "futilidade" e "ociosidade". Em The Gentleman's Magazine, de dezembro de 1787, por exemplo, há a seguinte consideração: "Há tempos e com frequência os romances são considerados não apenas como inúteis à sociedade mas até mesmo como perniciosos, por causa da moralidade muito medíocre e do ridículo modo de pensar que eles quase sempre inculcaram." ${ }^{36}$ Ideia muito semelhante foi expressa na Nouvelle bibliothéque d'un homme de goût, publicada em Paris em 1810: "Nós bem que

35. Para a recepção inglesa dos romances, tomei como referência o livro de Sandra Vasconcelos, A formação do romance inglês. Para a recepção francesa e portuguesa, tomei por base a pesquisa por mim realizada e parcialmente apresentada no livro Os caminhos dos livros. A recepção dos letrados brasileiros, publicada na imprensa, assim como os pareceres de censura franceses, portugueses e luso-brasileiros têm sido objeto de minhas pesquisas atuais.

36. The Gentleman's Magazine, vol. LVII, Dezembro de 1787. Assinado como "R. R. E." (Apud VASCONCELOS. A formação do romance inglês: ensaios teóricos, p. 579). 
gostaríamos de poder excluir dessa obra toda essa parte da nossa literatura los romances]; nós conhecemos sua inutilidade e mesmo seu perigo" ${ }^{37}$ Em língua portuguesa, a situação não era muito diferente, como se vê no comentário feito, em 1812, no Correio Braziliense, publicado em Londres por Hipólito José da Costa: "A immensidade de novellas que se tem publicado durante o seculo passado, e neste, a insipidez, inutilidade, e muitas vezes depravaçaõ destas publicaçoens, tem feito characterizar esta sorte de composiçoens, como uma leitura somente propria de espiritos frivolos, e como um emprego inutil, quando naõ seja de consequencias funestas á moral do leitor." ${ }^{38}$ Em Lisboa, poucos anos depois, o Marquês de Penalva, censor régio, batia na mesma tecla ao avaliar uma "Traducçaõ de Ingles, q’tem p p ${ }^{\mathrm{r}}$. titulo Contos do Castelo, ou os Illustres Emigrados", que buscava autorização de impressão em 1817: "detesto esta alluviaõ de Novellas quazi sempre perigozas, e raras vezes uteis". 39

Parte do descrédito do gênero vinha de sua associação aos públicos amplos, provocando comentários pejorativos sobre o interesse que o romance despertava entre vastas camadas de leitores, no interior do qual se destacam alguns grupos específicos: mulheres, jovens e pobres. Quando estes três elementos se somavam, ou seja, no caso das jovens mulheres sem recursos financeiros, as críticas eram ainda mais mordazes, como se vê nas "Reflexões rápidas sobre o romance moderno”, publicadas em The Lady's Magazine, de 1780: "Os romances [...] são os motores poderosos com que o sedutor ataca o coração feminino; e, se pudermos julgar a partir da experiência cotidiana, suas intrigas raramente são preparadas em vão. [...] A Srta., filha do alfaiate, fala agora com tanta familiaridade a sua confidente, A Srta. Polly Staytape, de pretendentes

37. BARBIER, Antoine Alexandre e LE MOYNE DESESSARTS (Nicolas Toussaint). Nouvelle bibliothéque d'un homme de goût, entiérement refondue, corrigée et augmentée, contenant des jugemens tirés des journaux les plus connus et des critiques les plus estimés, sur les meilleurs ouvrages qui ont paru dans tous les genres, tant en France que chez l'étranger jusqu'à ce jour. Paris: chez Arthus Bertrand, 1810, Tomo V, p. 1.

38. "Portugal. Atala ou os Amantes do deserto, a armonia da religiaõ Christaã com as scenas da natureza, e paixoens do coraçaõ humano. Lisboa. 1810. 1 vol. em 12. p. 157." In: Correio Brasiliense ou Armazem Literario, Londres: "impresso por W. Lewis, Na Oficina do Correio Braziliense, St John Square, Clerkenwell." Outubro 1812, p. 590.

39. Parecer elaborado pelo censor Marquez de Penalva para "Contos do Castelo ou os ilustres emigrados”. RMC - Caixa 85 - 1817 - XI - 15 . 
e sentimentos quanto as mais educadas moças da alta sociedade". ${ }^{40}$ Contra os jovens e suas leituras se batiam também os censores franceses, como se vê na avaliação do romance intitulado Lisady de Rainville: "deve-se ter cuidado em afastar sofismas deste tipo do espírito das pessoas jovens que fazem dos romances sua leitura demasiadamente ordinária”. ${ }^{41}$ Francisco Xavier de Oliveira, censor régio em Portugal, preocupava-se não apenas com as mulheres, mas com a difusão da leitura entre as camadas populares. Analisando o romance de cavalaria "História de Carlos Magno", caracterizou seu público com desprezo: "esta Obra tem taõ grande voga entre anossa gentalha que naõ há Sapateiro, Lacaio e Alfaiate, que naõ esteja fornecido d'hu exemplar [...] o que lhes-entorpece o espirito, e o-conserva sempre em hu estado debrutal estupidez." ${ }^{42}$ No Brasil, o padre pernambucano Miguel do Sacramento Lopes Gama publicou, na década de 1830, diversos textos em que aconselhava manter as mulheres longe dos livros, repetindo ideias acerca da influência dos romances sobre o comportamento feminino: "O que estraga os costumes, o que perverte a moral é, por exemplo, a leitura de tanta novela corruptora, onde se ensina a filha a iludir a vigilância de seus pais para gozar de seu amante, à esposa a bigodear o esposo etc. etc." ${ }^{43}$ Embora os comentários depreciativos com relação ao gênero romanesco e aos leitores tidos como mais afeitos a ele estivessem espalhados por todos os lados, o mais comum no final do XVIII e início do XIX não era a rejeição ao gênero como um todo e sim a distinção entre romances bem sucedidos (ou, ao menos, toleráveis) e romances inaceitáveis.

Nesses casos, também se observa uma notável homogeneidade nos critérios de avaliação. Um dos mais empregados era a aferição da moralidade do texto, já que todos acreditavam que a leitura provocava, necessariamente, efeitos sobre o leitor. No caso dos romances, ao preceito horaciano da mistura entre

40. "Cursory Thoughts on the Modern Novel". The Lady's Magazine, vol. XI, suplemento para 1780 (Apud VASCONCELOS. A formação do romance inglês: ensaios teóricos, p. 577).

41. Bulletins hebdomadaires des décisions concernant les ouvrages soumis à l'inspection des censeurs. Parecer 223, última semana de novembro de 1810. Série $F^{18^{\circ}}$ I 148. Archives Nationales. Paris.

42. Parecer assinado por Francisco Xavier de Oliveira, datado de 6 de maio de 1797. Desembargo do Paço, Repartição da Corte, Estremadura e Ilhas, março 1932, caixa 1759. ANTT

43. GAMA. "O nosso gosto por macaquear". In: O Carapuceiro. 
instrução e deleite associou-se a moralização, que seria obtida por enredos em que o vício fosse castigado e a virtude, premiada. Obras em que estes elementos estavam presentes eram enaltecidas tanto em resenhas críticas como em pareceres da censura. É o que se vê, por exemplo, na avaliação produzida pela censura portuguesa acerca de "Cecile fille de Achmet", avaliada pelos censores como "huma Novela, q. edifica, e recrea ao mesmo tempo [...] instruindo a cada passo

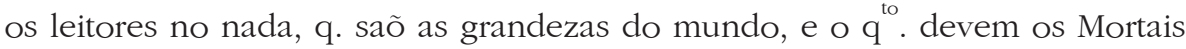
procurar, e amar a virtude, aborrecendo os vicios." A imprensa inglesa ecoou ideia semelhante ao publicar, em 1820, texto em que Mrs. Barbauld assevera: "não é necessário apoiar o crédito dessas obras [romances] apenas no divertimento, pois é certo que tiveram um forte efeito na inspiração de princípios e sentimentos morais. É impossível negar que os sentimentos de virtude mais entusiasmados e comoventes podem ser encontrados em muitas dessas composições e foram absorvidos por seus jovens leitores". ${ }^{45}$

Entretanto, o efeito moralizador não era suficiente para garantir uma avaliação positiva para um romance, mesmo quando o julgamento do texto era elaborado por um censor, como ocorreu quando da passagem pela censura francesa do livro "La véritable école des femmes ou histoire de Gesmina Gusman": "a este romance, cujo fundo é bastante comum, não faltaria um interesse doce, moral e decente se o estilo do autor não cansasse por sua pretensão, incorreção e difusão". ${ }^{46}$ Da mesma forma, a passagem pela censura lusitana do livro "A virtude exercitada ou heroismo chines" deixou claro que não bastava atender às expectativas quanto à edificação do leitor: "Ainda que nesta historia se encontrem na verde. alguãs regras dehuã moral solida, e sãa, e alguns exemplos de virtude, que fazem honra a memoria do seo heroe, todas estas couzas em si preciozas se achaõ como involvidas em lodo pela falta de ordem, de nexo, ededuçaõ, por

44. Parecer relativo a "Cecile fille de Achmet, 30 empereur des turcs", exarado em 7 abr 1788 e assinado por Luis de Santa Clara Povoa, Pascoal José de Melo e Francisco Pires de Carvalho e Albuquerque. RMC - Censuras e Pareceres - Caixa 14, 1788, no 17.

45. Mrs. Barbauld. "On the origin and progress of novel-writing". The British novelist; with an Essay, and Prefaces Biographical and Critical. 1820. (Apud VASCONCELOS. A formação do romance inglês: ensaios teóricos, p. 587).

46. Parecer 110, primeira semana de novembro de 1810. Série $\mathrm{F}^{18^{*}} \mathrm{I} 148$. Archives Nationales. Paris. 
muitas inepcias, e futilides. que mistura o A. por hum estylo pueril, improprio, e falto de correcçaõ deque uza pela falta de critica, e de bomsenso." ${ }^{47}$

Esperava-se, também, que a intriga despertasse e mantivesse o interesse do leitor, como afirmou o censor francês encarregado da avaliação do livro "Erreurs et mystère": seu "estilo é caracterizado pela facilidade, correção e até mesmo pela graça. Sua moral é pura, mas é fraco do ponto de vista da intriga e do interesse, e, como muitos outros, não apresenta um desenlace satisfatório." ${ }^{48}$ Os críticos que escreviam do outro lado da Mancha concordavam com os franceses e portugueses, como se vê no já citado texto "Sobre a origem e o avanço da escrita de romances": "a invenção de uma história, a escolha do incidente adequado, a ordonnance do plano, as belas descrições ocasionais e, sobretudo, o amor, piedade, alegria, angústia, êxtase ou indignação, juntamente com a moral séria e comovente que resulta do todo, envolvem talentos da mais alta espécie, e deveriam ser valorizados na mesma proporção." ${ }^{49}$ A esses elementos devem-se acrescentar os critérios de avaliação elencados pelo autor de "Observações gerais sobre os romances modernos", publicado no The Lady's Magazine: "Numerosas situações são, é verdade, descritas nos romances de hoje; mas de maneira tão fria e tão mesquinha que não ficamos minimamente interessados nas personagens a respeito de quem lemos; personagens que não conseguimos recomendar entusiasticamente, embora não se encontre absolutamente nenhum defeito em seu procedimento ou em sua conduta. São, a rigor, desenhados com tanta submissão, tanta insipidez que ficamos propensos a bocejar em cima das páginas sob nossa inspeção; sendo movidos unicamente pela curiosidade a chegar até o final da história".

47. Parecer relativo a "A virtude exercitada ou heroismo chines", exarado em 20 nov. 1788 e assinado por Francisco Pires de Carvalho e Albuquerque, António de Santa Marta Lobo da Cunha, Pascoal José de Melo. RMC - Censuras e Pareceres - Caixa 14, 1788, no 65.

48. Bulletins hebdomadaires des décisions concernant les ouvrages soumis à l'inspection des censeurs. Parecer 462, terceira semana de março de 1811. Série F18* I 148. Archives Nationales. Paris.

49. Mrs. Barbauld. "On the origin and progress of novel-writing". The British novelist; with an Essay, and Prefaces Biographical and Critical. 1820 (Apud VASCONCELOS. A formação do romance inglês, p. 585).

50. "General observations on modern novels". The Lady's Magazine, vol. XVIII, Setembro de 1787 (Apud VASCONCELOS. A formação do romance inglês, p. 578). 
Também recorrente é a preocupação com a verossimilhança da narrativa, como se vê na avaliação feita pela censura francesa da obra "Charles de Montfort": "este romance escrito com facilidade contem uma narrativa tocante e verossímil dos desvarios ocasionados pelos remorsos e do triste fim de uma jovem exposta, durante a ausência de seu marido, a seduções das quais ela não soube escapar. Este fundo ligeiro permitiu ao autor, M. Thierry de Mauregard, traçar cenas de um interesse muito vivo, as quais não perdem seu efeito apesar de alguns arrastamentos."

Esses poucos exemplos, extraídos de centenas de documentos em que letrados comentam romances, parecem deixar claro que os discursos se repetiam, independentemente das diferenças existentes entre os lugares de onde se falava - lugares tão distintos como a industrializada Inglaterra e o Brasil escravista -, o que parece mostrar que as condições sócio-econômicas têm menos peso do que a formação cultural e do que as conexões estabelecidas pelos homens de letras.

Um dos fortes pontos de contato entre letrados europeus e brasileiros é o conhecimento das artes retóricas e poéticas, que ocupavam um lugar central na formação escolar. Ainda que elas não dedicassem nenhum, ou quase nenhum, espaço para a reflexão sobre romances, elas instruíam sobre os critérios de avaliação de narrativas e formavam ideias sobre a função das Letras. Livros como Lectures on rhetoric and belles lettres do escocês Hugh Blair podem ter contribuído para criar um pensamento comum sobre os romances na Europa e no Brasil. ${ }^{52}$ Publicado em 1783, foi um dos primeiros manuais de retórica - se não o primeiro - a reservar um pequeno espaço para o exame do que Blair chamou de "Fictitious history". Em apenas quatro páginas, o retor discorreu sobre essa "muito numerosa, embora, em geral, insignificante classe de escritos", muitas vezes "inocentes", mas frequentemente "insípidos", cuja influência parecia considerável "tanto na moral quanto no gosto de uma nação", afirmando que o propósito das obras "conhecidas pelo nome de romances e

51. Bulletins hebdomadaires des décisions concernant les ouvrages soumis à l'inspection des censeurs. Parecer 284, terceira semana de dezembro de 1810. Série $F^{18} *$ I 148. Archives Nationales. Paris.

52. MARTINS. A fonte subterrânea - José de Alencar e a retórica oitocentista, p. 12-14.

53. BLAIR. Lectures on rhetoric and belles lettres. 
novelas" era instruir pelo exemplo, tornando "a virtude amável e o vício odioso". Blair repetia e difundia ideias comuns à época ao explicitar o desprezo pelo gênero ("insignificante classe de escritos") e dar atenção à dimensão moral (tornar a virtude amável e o vício odioso) e instrutiva que os escritos poderiam ter. Outros elementos do discurso corrente sobre os romances também são mencionados quando o retor chama a atenção para a necessidade de ter "histórias bem urdidas" para que se obtenha o "efeito" desejado, que será superior em eficácia à "instrução pura e simples". E, finalmente, quando esclarece que "não é a natureza desse tipo de escrito em si mesma, mas sua execução falha, que o pode expor a qualquer desprezo." ${ }^{54}$

A difusão das ideias sobre como avaliar a cada dia mais numerosa produção de romances contou também com o grande apoio de revistas como a Edinburgh Review (Edimburgo), a Quaterly Review (Londres), Revue des Deux Mondes (Paris), Revue Britanique (Paris), que tinham circulação mundial e presença certa no Rio de Janeiro. ${ }^{55}$ A divulgação dos textos publicados nessas e em outras revistas era ainda maior tendo em vista a prática da tradução de artigos de interesse para publicação em outros periódicos. Esse era o propósito, por exemplo, da Revista Nacional e Estrangeira - escolha d'artigos originaes e traduzidos por uma sociedade de litteratos brazileiros, publicada no Rio de Janeiro, entre 1839 e 1841. Os responsáveis pela publicação - João Manoel Pereira da Silva, Josino do Nascimento Silva, e Pedro d'Alcantara Bellegarde - anunciavam que eram "assignantes de grande numero de periódicos, tanto inglezes como francezes, publicados com o titulo de Revista", dos quais extrairiam os artigos para tradução, tomando por modelo a "Revista Britannica". Foi por meio de uma destas traduções que os leitores tomaram conhecimento do texto "Juizo da Revista de Edimburgo sobre a literatura franceza contemporânea",

\section{BLAIR. Lectures on rhetoric and belles lettres, p. 417.}

55. Sandra Vasconcelos verificou a presença desses títulos em catálogos de gabinetes de leitura do Rio de Janeiro do século XIX. VASCONCELOS. Cruzando o Atlântico. In: ABREU, Márcia. (org.) Trajetórias do romance, p. 369-370.

56. Revista Nacional e Estrangeira - escolha d'artigos originaes e traduzidos por uma sociedade de litteratos brazileiros. No. 1. Rio de Janeiro: Typ. de J. E. S. Cabral, 1839, p. 1.

57. Seção "Litteratura". Artigo "Juizo da Revista de Edimburgo sobre a literatura franceza contemporânea." Revista Nacional e Estrangeira - escolha d'artigos originaes e traduzidos por uma sociedade de litteratos brazileiros. Julho - No. 3. Rio de Janeiro: Typ. de J. E. S. Cabral, 1839. 
em que se criticaram duramente romancistas franceses como Balzac, Hugo, Sue, Janin, Sand, Kock, Lacroix devido à má concepção de seus enredos e inadequada seleção de episódios, à infeliz construção de suas personagens, à falta de moralidade de suas narrativas e à inverossimilhança. Dentre as dezenas de romances comentados apenas um - Le Dernier Jour d'un Condamné, de Victor Hugo - havia sido "traduzido em portuguez" e estava "a venda na loja de livros da rua da Quitanda, n. 77", como indica nota do tradutor aposta ao texto. Assim, antes de conhecer os livros, os leitores já saberiam o que se dizia sobre eles na Europa e poderiam conhecer (ou reconhecer) os critérios de avaliação de romances empregados nas mais prestigiosas revistas europeias.

Assim, por meio da circulação de livros e revistas, bem como por meio do trânsito dos homens e mulheres que os liam e escreviam, os compravam e vendiam, formava-se uma comunidade letrada transnacional que partilhava referências, leituras e modos de ver a literatura e os romances.

\section{Problemas para a história literária}

Os dados sobre o comércio e a leitura de romance compõem um quadro bastante distinto daquele que se vislumbra nas histórias literárias.

Primeiramente, porque elas se concentram sobre a produção dos autores canônicos, dando destaque a obras que, muitas vezes, tiveram pouca ou nenhuma repercussão em sua própria época, ao mesmo tempo em que deixam de fora a maior parte dos livros para os quais se voltava a preferência do público como se viu, a maior parte das obras de destaque nas importações, no comércio livreiro e nas leituras realizadas na Biblioteca Nacional encontra-se ausente das histórias literárias convencionais. Enquanto os leitores interessados pela ficção brasileira buscavam a Biblioteca Nacional e Pública do Rio de Janeiro para ler

58. Provavelmente, o juízo negativo dos críticos não perturbou o interesse da maior parte dos leitores, tendo em vista que uma das obras criticadas - La Salamandre, de Eugène Sue - foi um dos mais lidos romances na Biblioteca Nacional e Pública do Rio de Janeiro.

59. Para uma discussão sobre os vínculos mantidos pelos letrados de diferentes partes do mundo, ver CASANOVA. A República Mundial das Letras e JURT; Le champ littéraire entre le national et le transnational. In: SAPIRO (org). L'espace intelectuel en Europe. 
as obras de Teixeira e Souza e de Joaquim Manoel de Macedo, ${ }^{60}$ muitas histórias da literatura brasileira sequer registram as obras do primeiro e apresentam o segundo como um autor menor, comentando apenas A Moreninha. Da mesma forma, as histórias literárias europeias não costumam dar destaque a Eugène Sue e Alexandre Dumas, embora fossem eles os autores contemporâneos de maior repercussão entre os leitores de meados do século. Em contrapartida, obras de destaque nas histórias literárias podem ter pouca ou nenhuma importância entre os leitores da época, como as de Stendhal, George Sand e Alfred de Vigny, sempre presentes nas histórias literárias, mas bastante ausentes nos interesses dos leitores franceses. ${ }^{61}$ Não é à toa, portanto, que Martyn Lyons afirma: "as omissões nas nossas listas de best-sellers são às vezes mais significativas do que os sucessos literários, sobretudo quando a obra em questão foi particularmente apreciada pela crítica literária”. ${ }^{2}$

Considerar as preferências de leitura levaria não apenas a ampliar o corpus de obras, mas também a rever a cronologia com a qual normalmente se trabalha. Por exemplo, Dom Quixote e História de Gil Blas são obras analisadas em sua relação com os séculos XVII e XVIII, respectivamente, mas estão entre as mais lidas, vendidas e anunciadas no início do século XIX, podendo ser entendidas, portanto, não apenas em sua relação com o momento em que foram escritas mas na longa duração do interesse que despertaram. Enquanto as histórias literárias se organizam em função das mudanças de paradigma e de propostas estéticas, o interesse dos leitores se mantém estável, por décadas ou, até mesmo, séculos. Os historiadores dos Annales chamaram a atenção para a lentidão nos processos históricos, reflexão muito apropriada para a compreensão dos interesses dos leitores de ficção, pelo menos até o advento do folhetim. Como lembrou Franco Moretti, uma história da literatura atenta à leitura e à circulação de livros seria uma "história de normas", uma "configuração menos inovadora, muito 'mais plana' do que aquela a que estamos acostumados". ${ }^{3}$

60. ROCHA. Biblioteca Nacional e Pública do Rio de Janeiro.

61. LYONS. Les best-sellers. In: CHARTIER \& MARTIN. Histoire de l'édition française.

62. LYONS. Les best-sellers. In: CHARTIER \& MARTIN. Histoire de l'édition française. p. 414.

63. MORETTI. Atlas do romance europeu, p. 160. 
A longa atração exercida por um conjunto de obras deixa evidente a convivência entre estilos e formas, colocando em xeque as rupturas que marcam as periodizações estabelecidas pelas histórias literárias, que, em geral, organizam os escritos em "escolas literárias", às quais corresponderiam determinados temas e traços estilísticos, supostamente representativos do interesse de uma época. No entanto, escritos tão diversos como Gil Blas e Aventuras de Telêmaco estão entre as obras de maior difusão na primeira metade do século XIX, tanto no Brasil como na França, o que traz problemas para a caracterização do Romantismo como o "movimento literário" capaz de expressar esta época. Analisando a situação francesa, Martyn Lyons observa:

Se é possivel tirar uma conclusão geral, pode-se afirmar que, apesar de Rousseau, Lamartine, Byron e Scott, a cultura francesa permaneceu profundamente clássica e que a estética do Grande Século deixou uma marca indelével sobre a história do gosto francês. [...] O romantismo literário não foi nada além de um fator marginal no consumo literário francês. (...) O romantismo não parece uma noção adequada para resumir os gostos da época. Ele parece ter sido muito mais a crista fugitiva de uma onda sobre um vasto oceano de classicismo e catolicismo. ${ }^{64}$

Tendo em vista os dados sobre as preferências dos leitores fluminenses e sobre a oferta de livros no Rio de Janeiro é possível acreditar que suas afirmações têm um alcance maior do que ele supôs, uma vez que não apenas a cultura francesa, mas também a brasileira (e, provavelmente, a do restante do mundo ocidental) permaneceu profundamente ligada aos textos dos séculos XVII e XVIII, revelando menos interesse por autores e obras tidas como referências centrais do Romantismo.

Assim, as tradicionais "características" da "escola romântica" são insuficientes para compreender o panorama literário da primeira metade do século XIX, não apenas porque elas não têm pertinência se considerados os livros de maior difusão, mas também porque um dos elementos centrais na apreciação da literatura oitocentista é sistematicamente desprezado: a moral. É verdade que os autores do final do XIX e do século XX recusaram-se a identificar finalidades

64. LYONS. Les best-sellers. In: CHARTIER \& MARTIN. Histoire de l'édition française. p. 427 e 436. 
externas aos textos, centrando seu interesse em aspectos formais. Entretanto, constitui flagrante anacronismo olhar para a primeira metade do XIX com essa perspectiva, uma vez que os homens de letras daquele momento - aí incluídos os escritores - estavam convencidos de que os romances tinham uma finalidade prática. As centenas de textos críticos produzidos na Inglaterra, Brasil, Portugal e França permitem perceber que os letrados de final do século XVIII e início do XIX esperavam que um romance fosse capaz de moralizar e instruir, ao mesmo tempo em que deleitasse e emocionasse os leitores. Além disso, julgavam os romances do ponto de vista do estilo (elocução), linguagem, invenção, disposição da matéria (ordem, nexo e dedução), elaboração das descrições, construção de personagens e do enredo (que deveria ser verossímil, com um desenlace interessante, evitando-se os arrastamentos). ${ }^{65}$ É evidente a distância entre estes critérios de avaliação e o que se encontra em uma história literária convencional, que apresentará o subjetivismo, individualismo, nacionalismo, religiosidade etc. como elementos centrais da literatura do início do século XIX e tratará os romances, as poesias e as peças teatrais com igual relevo, esquecendo-se do baixo lugar ocupado pela prosa ficcional na hierarquia dos gêneros.

As semelhanças nas avaliações produzidas pelos letrados, a sincronia nos interesses dos leitores e a presença simultânea de um conjunto de obras em diferentes partes do globo faz repensar também a centralidade que a questão nacional ocupa na escrita das histórias literárias. A maior parte delas se fecha sobre um território e examina a produção aí publicada, desconhecendo ou dando pouca relevância aos contatos externos, exceto quando se trata de articular as obras nacionais a textos canônicos destacados em histórias literárias de outras nações. Enquanto isso, os leitores transitam por obras de diversas nacionalidades, sem se concentrar exclusivamente sobre a produção local. Até mesmo a separação política do Brasil em relação a Portugal, tão enfatizada nas histórias literárias, parece ter impacto reduzido sobre o gosto dos leitores em matéria de ficção. Quando se trata da leitura de romances no Brasil até o meado

65. A profusão de detalhes e digressões (longueurs) parecia agradar apenas aos leitores ingleses. A. N. Pigoreau é um dos que comenta a diferença entre franceses e ingleses no gosto pelos detalhes que retardam o andamento da narrativa: "Le Français vif et léger ne lit un roman que pour se distraire quelques instants; il veut qu'on le conduise au but pour voi la plus courte. L'Anglais, flegmatique, aime à s'appesantir sur les détails, et ne veut arriver au dénouement qu'après s'être promené dans le longs circuits d'un labyrinthe". (PIGOREAU, Petite bibliographie biographico-romancière, 5o suplemento, p. 18). 
do século XIX, Portugal parece ser uma referência incontornável, não apenas pelo interesse despertado por obras lusas, como o pouco conhecido Lances da ventura, mas também pela relevância das traduções e edições portuguesas no cenário brasileiro da primeira metade do Oitocentos.

Se modificações políticas podem não afetar diretamente o gosto dos leitores, mudanças internas ao mundo das letras podem ter impacto imediato e estrondoso. Na primeira metade do século XIX, o fator de maior relevância para a compreensão do comportamento do público parece ter sido o surgimento dos folhetins. Sua entrada em cena causou alteração significativa nos modos de acesso à ficção e nos interesses dos leitores tanto na Europa como no Brasil, que se voltaram avidamente para as produções contemporâneas depois de terem se mantido ligados a um restrito conjunto de obras por décadas.

Uma história literária atenta à leitura e aos valores próprios à época seria levada, portanto, a rever seus marcos tradicionais, ampliar o corpus de textos com os quais trabalha, centrando-se não apenas na produção dos escritos e nas obras canônicas de determinados territórios nacionais, o que pode trazer ganhos para a compreensão do passado e da literatura nele produzida, lida e apreciada.

Connected by fiction: circulation and reading of novels in Europe and Brazil

Abstract: This article presents and analyses the cultural connections established between Europe and Brazil through the novels in circulation in the first half of the 19th century. The text is divided into three parts. At first, we present information about book trade and novel reading in Rio de Janeiro and Paris, providing data about the novels that aroused greater interest in these places. Secondly, we analyse the manners in which novels were read by cultivated men in Europe and Brazil in the first half of the 19th century. In the third and final part, we discuss the consequences that the knowledge of readers' preferences and that 19th century critical assessments may have for literary historiography.

Keywords: Novel, Globalisation, History of literature. 


$$
\text { Referências }
$$

ABREU, Márcia. Os caminhos dos livros. Campinas: Mercado de Letras/ALB/FAPESP, 2003.

BLAIR, Hugh (1866). Lectures on rhetoric and belles lettres, with a memoir of the author's life to which are added copious questions; and an analysis of each lecture by Abrahams Mills. Philadelphia: T. Ellwood Zell \& Co.

CASANOVA, Pascale. A república mundial das Letras. São Paulo: Estação Liberdade, 2002.

COOPER, Frederick. What is the concept of globalization good for? An African historian's perspective. African Affairs, 100, 2001. p. 189-213.

GAMA, Miguel do Sacramento Lopes. O nosso gosto por "macaquear". In: O Carapuceiro, 14 de janeiro de 1840. Reproduzido em O Carapuceiro: crônicas de costumes. Organização Evaldo Cabral de Mello. São Paulo: Companhia das Letras, 1996. Coleção Retratos do Brasil.

GRUZINSKY, Serge. Les quatres parties du monde - histoire d'une mondialisation. Paris: Éditions de La Martinière, 2004.

HEINEBERG, Ilana. La suite au prochain numéro: formation du roman-feuilleton brésilien à partir des quotidiens Jornal do Commercio, Diário do Rio de Janeiro et Correio mercantil (1839-1870). Université de la Sorbonne Nouvelle - Paris III, 2004.

JURT, Joseph. "Le champ littéraire entre le national et le transnational". In: SAPIRO, Gisèle (org). L'espace intelectuel en Europe. Paris: La Découverte, 2009.

LYONS, Martyn. (1990) Les best-sellers. In: CHARTIER, Roger \& MARTIN, Henri-Jean. Histoire de l'édition française. Paris: Fayard/Promodis, p. 409-448. 1a edição 1985.

MANÇANO, Regiane. Livros à venda: presença de romances em anúncios de jornais. Campinas: Programa de Pós-graduação em Teoria e História Literária, Instituto de Estudos da Linguagem, UNICAMP, 2010.

MARTINS, Eduardo Vieira. A fonte subterrânea - José de Alencar e a retórica oitocentista. Londrina: Eduel/São Paulo: Edusp, 2005.

MORETTI, Franco. Atlas do romance europeu. São Paulo: Boitempo, 2003.

OUTEIRINHO, Fátima. As traduções da obra de Rousseau em Portugal: texto e paratexto. Revista da Faculdade de Letras Línguas e Literaturas. Porto, XII, 1995. p. 395-418.

PIGOREAU (1823), A. N. Petite bibliographie biographico-romancière, ou Dictionnaire des romanciers tans anciens que modernes, tant nationaux qu'étrangers; avec un mot sur chacun d'eux et la notice des romans qu'ils ont donné, soit comme auteurs, soit comme traducteurs, précedé d'un catalogue des meilleurs romans publiés depuis plusiers années, et suivi de tableaux propres à en faire connaître les différents genres et à diriger dans le choix des ouvrages qui doivent faire la base d'un cabinet de lecture. Paris, Pigoreau Librarie, 1821-1828.

ROCHA, Débora Cristina Bondance. (2011) Biblioteca Nacional e Pública do Rio de Janeiro - um ambiente para leitores e leituras de romances (1833-1856). Campinas: Programa de Pós-graduação em Teoria e História Literária, Instituto de Estudos da Linguagem, UNICAMP, 2011.

SCHAPOCHNIK, Nelson. Edição, recepção e mobilidade do romance Les mystères de Paris no Brasil oitocentista. In: Varia história. vol. 26 n. 44, Belo Horizonte Jul/Dec 2010.

VASCONCELOS, Sandra Guardini T. Cruzando o Atlântico: notas sobre a recepção de Walter Scott. In: ABREU, Márcia. (org.) Trajetórias do romance: circulação, leitura e escrita nos séculos XVIII e XIX. Campinas/São Paulo: Mercado de Letras/FAPESP, 2008. p. 351-374. 
Belo Horizonte, p. 15-39

VASCONCELOS, Sandra Guardini T. A formação do romance inglês: ensaios teóricos. São Paulo: Hucitec/FAPESP, 2007.

VILLALTA, Luiz Carlos. Reformismo ilustrado, censura e práticas de leitura: usos do livro na América Portuguesa. São Paulo: Programa de Pós-graduação em História, FFLCH-USP, 1999. [Tese de Doutoramento]. 
